\title{
Experimental \&FEA Assessment of Modification in Portal Axle Shaft
}

\author{
Mr. Niket N. Lachake, Prof. A. B. Gaikwad \\ ${ }^{\#}$ Department of Mechanical Engineering, Dr. D. Y. Patil School of engineering, Charholi(Bk), Pune- \\ 412105, SavitribaiPhule Pune University.
}

\begin{abstract}
Portal axles (or portal gear) are designed for off-road driving conditions. The axle tube is above the center of the wheel hub and a reduction gearbox present within the hub. Axle tube is installed between the wheel and the axle shaft to give more ground clearance to the vehicle. It is the shaft which must have higher strength and toughness.Since composite materials are having promising properties, which can reduce the weight and almost equal to conventional material properties. In this paper portal axle shaft is analyzed by Finite Element Analysis considering varying parameters i.e. rib thickness and hollow shaft thickness and are consider. Some of the parameters are kept constant which are the depth of spokes, the rib fillet radius and the number of spokes. The Torsional strength of the shaft compared for three different models. The modeling and simulation of spur gears in placed portal axle is important to predict the actual motion behavior. However, gear train design in portal axle is difficult to study comprehensively due to their relatively low cost and short product life cycle. In this study, modal analysis of portal axle shaft is simulated using Finite Element Method(FEM).
\end{abstract}

Keywords:EN-24, FEM, torsion test, Taguchi approach, Torsion Testing Machine.

\section{Introduction}

A portal axle unit is installed between the wheel and the axle shaft to give higher ground clearance to the vehicle. It allows driving on off-road so that the vehicle can go over high terrains and obstacles. Compared to normal axel, portal axles enable the vehicle to gain a higher ground clearance, as both axel tube and differential casing are tucked up higher under the vehicle. The difference between normal axel and portal axel are showed in the below figure 1

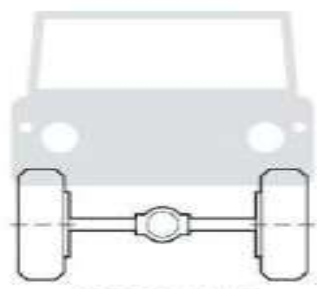

NORMAL AXLE

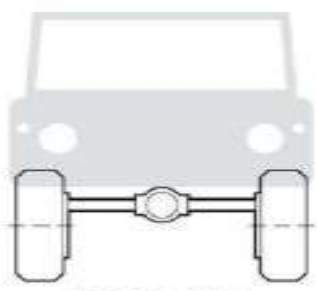

PORTAL AXLE

Fig. 1: Difference between normal axel and portal axel

The input shaft of portal axle receives the power from differential unit and sends it to portal axle unit and the output shaft transfer the power from portal axle unit to road wheels. Shear strength is a material's ability to resist forces that can cause the internal structure of the material to slide againstitself.Adhesives tend to have high shear strength.

In engineering, shear strength is the strength of a material or component against the type of yield or structural failure where the material or component fails in shear. The shear strength is the load that an object is able to withstand in a direction parallel to the face of the material, as opposed to perpendicular to the surface. Shear strength can be determined in a torsion test where it is equal to tensional strength. It is reported in pounds per square inch, based on the area of thesheared edge.

The shear strength of a structural adhesive is the maximum shear stress in the adhesive prior to failure under tensional loading. The shear strength of steel depends on the type of steel it is. In general, ductile materials (such as aluminum) fail in shear, whereas brittle materials (such as cast iron) fail in tension. It is important to understand the amount of weight (or load) that a structure can support. It is especially important to understand the forces that are applied to a structure in different directions. When a shaft is subjected to a torque or twisting, a shearing stress is produced in the shaft. The shear stress varies from zero in the axis to a maximum at the outside surface of the shaft produced in the shaft. The shear stress varies from zero in the axis to a maximum at the outside surface of the shaft. 


\section{Torsion analysis of the shaft}

\section{LiteratureReview}

Evaluation of torsion in shaft has been practiced by engineers in the past few decades and it is the key of importance in the design of shafts. Extremely high torsion resulting from overloading can cause higher fatigue failure or complete shaft breakage (Xiaoleiet al.2011). The failure in shafts normally occurs at the stress concentration area found in splined joints shaft and keyway shaft which can eventually lead to the fracture of gear shaft [59]. These stress concentrations on critical areas can be reduced by redesigning the structure of the shaft (Heisler, 1999; Jianping and Guang, 2008). In practice, engineers apply the available standards for designing shaft based on their shaft design criteria. The standards for shaft design such as the ANSI or ASME standards provide a range of shaft design criteria extracted from verified analytical solution. However, these standards are only limited to certain type of shaft design and it lack the depth of understanding of how torsion can affect the whole shaft design. Furthermore, when it comes to customizing the shaft design, these standards may not be applicable In the past decade, FEA was proved to be effective by authors (Li, 2001; Bayrakceken et al., 2007; Crivelli et al., 2011) in evaluating torsion in shafts and also to help them in the investigation of failure analysis of the shaft applications. Mutasher (2009) applied FEA to determine the tensional strength of the hybrid aluminum composite drive shaft and good agreement was obtained between the finite element predictions and the experimental results. Göksenliand Eryürek (2009) applied FEAto perform tensional stress analysis on the keyway shaft of an elevator. The acceptable radius of the keyway corner was considered through studying the relationship between shaft stress and radius of the keyway corner of theshaft.

\section{Taguchi method for shaft optimization}

There has been a lot of research on the analysis of shaft in various applications. However, the strength and weight are always a major concern in shafts design. Shaft designers and engineers are constantly looking into ways to redesign shaft based on a number of parameters to achieve higher strength to weight ratio. Usually, the effect of one parameter to the shaft strength is analysed separately. This type of analysis can be less effective when considering a number of parameter because one parameter may affect another. To study the trade-offs that exist between these conflicting design goals and to explore design options, one needs to formulate the optimization problem to achieve the desiredobjective.

Taguchi method is an effective optimization method that has been applied in various field of research. It is a statistical method developed by Genichi Taguchi to improve the quality of manufactured goods. Recently, it was also being applied in engineering for optimizing mechanical design (Byrne and Taguchi, 1987; Box and Bisgaard, 1988; Ross, 1996). In this method, the orthogonal array (OA) is proposed depending on the factors and variables to be optimized. Kotcioglu et al. (2012) have performed experimental investigation for optimizing design parameters in a rectangular duct with Plate Fins heat exchanger by using Taguchi Method. Gunes et al. (2011) applied Taguchi method to determine the optimum values of the design parameters in a tube with equilateral triangular cross-sectioned coiled wire insert. From their research work, the effect of the design parameters was investigated by using Taguchi method. To date, Taguchi method was rarely applied in mechanical design problems such as in gear and shaft designs even though the optimization is proved effective (Byrne and Taguchi, 1987; Otto and Antonsson, (1991). Based on the above mentioned applications, Taguchi method can be used in optimizing shaftdesign.

\section{Problem statement}

The shaft of portal axle is weak near the point of the gear pair as it wears out due to excess torque applied over it. Thus In designing a shaft which can be used in robust conditions, engineers are seeking to design shafts which are capable to operate with sufficient strength but reduced weight for improved power to weight ratio. In recent survey of years it is seen that hollow shaft is more favoured than the solid shaft because it offers increased availability and lightweight with adequate tensional strength. However, when compared between the solid shaft and hollow shaft with equal section modulus, the tensional strength of the hollow shaft is reduced by nearly to half.

\section{Objective}

1) To develop a hollow shaft which has a rib model for the output shaft of the portal axle that can accurately simulate its tensional strength by using FEA.

2) To improve the tensional strength of the hollow shaft with rib model through parametric optimization by using TaguchiMethod

\section{Theoretical analysis}

Distortion energy theory (DET) is applied to determine the von Mises stress of the hollow shaft. DET (alsoknown as the von Misescriterion) postulates thatfailure is caused by the elastic energy associated with shear 
deformation. The hollow shaft is assumed to be ductile material, thus DET is valid and can be applied. DET considers the maximum axial stress in the transverse direction (perpendicular to the shaft axis) caused by the bending moment and the maximum shear stress caused by torque. For a hollow shaft, the maximum axial stress is:

$$
\sigma_{s}=\frac{32 M D}{\pi\left(D^{4}-d^{*}\right)}
$$

Similarly, the maximum shear stress is:

$$
\tau_{s t}=\frac{167 D}{\pi\left(D^{4}-d^{4}\right)} \text {, }
$$

Where Mis the bending moment, $T$ is the applied torque, $D$ is the external diameter of the hollow shaft, and $d$ is the internal diameter of the hollow shaft. The principal stresses can be determined with the known value of oxand $\tau x y$ as in the following:

$$
\sigma_{t, 2}=\frac{\sigma_{x}+\sigma_{y}}{2} \pm \sqrt{\left(\frac{\sigma_{t}+\sigma_{y}}{2}\right)^{2}+\tau_{v}^{2}} .
$$

For the plane stress state, the principal normal stresses when $\sigma y=0$, are:

$$
\sigma_{1}, \sigma_{2}=\frac{16}{\pi d^{3}}\left(M \pm \sqrt{M^{2}+T^{2}}\right) .
$$

Finally, the general equation for calculating the von Mises stress of the shaft is:

$$
\sigma_{e}=\left(\sigma_{1}^{2}-\sigma_{1} \sigma_{2}+\sigma_{2}^{2}\right)^{\frac{1}{2}} \text {. }
$$

In using the DET for determining the shaft tensional stress, there are few assumptions to be considered:

1. It is based on a two-dimensional schematicdiagram.

2. The effect of gravity and the mass of the shaft areneglected.

3. DET is only valid for ductilematerial.

\section{Finite Element analysis}

The finite element analysis (FEA) is a computational technique used to obtain approximate solution of boundary value problems in engineering. Simply stated, a boundary value problem is mathematical problem in which one or more dependent variables must satisfy a differential equation everywhere within a known domain of independent variables and satisfy specific conditions on the boundary of thedomain.

\section{i. FEAPre-processor:}

The pre-processor stage in the general FEA package involves the following:

a. Creating themodel

b. Defining the elementtype

c. Applying amesh

d. Assigning materialproperties

e. Applyloads

f. Applying boundaryconditions

\section{ii. Solution}

The Finite Element solver can be logically divided into three mains parts, the pre-solver, the mathematical engine $\&$ the post solver. The pre-solver reads the model created by the pre-processor $\&$ formulates the mathematical representation of the problem. All parameters defined in the pre-processing stage are used to do this, so if something is left out, pre-solver will complain to form the element stiffness matrix for the problem \& calls the mathematical engine which calculates the results (displacement, temperature $\&$ pressure etc.). The results are returned to the solver \& the post-solver is used to calculate strains, stresses, heat fluxes, velocities etc. for each node within the component or continuum. All these results are sent to a result file which may be thepost-processor.

\section{iii. Post-processor}

Here the results are read \& interpreted. They can be presented in the form of table, a contour plot, deformed shape of the component or the mode shapes $\&$ frequencies if frequency analysis is involved. Most post-processors provide an animation service, which produces an animation. Slices can be made through 3-D 
models to facilitate the viewing of internal stress patterns

Table I: Properties Used In FEA

\begin{tabular}{|l|l|l|l|}
\hline Material Property & Notation & EN24 & Unit \\
\hline Modulus of Elasticity & E & $2 \times 10^{5}$ & $\mathrm{MPa}$ \\
\hline Poisson Ratio & $\mathrm{V}$ & 0.3 & - \\
\hline Density & P & 7850 & $\mathrm{Kg} / \mathrm{m}^{3}$ \\
\hline Tensile Strength & Syt & 1279 & $\mathrm{MPa}$ \\
\hline
\end{tabular}

There are certain common steps in formulating a finite element analysis of a physical problem, whether structural, fluid flow, heat transfer, vibration and some other problem. These steps are usually embodied in commercial finite element software packages. There are three main steps, namely: preprocessing, solution and post processing. The preprocessing (model definition) step is critical. This step includes; define the geometric domain of the problem, the element types to be used, the material properties of the elements, the geometric properties of the elements (length, area and the like), the element connectivity (mesh the model), the physical constraints (boundary conditions) and the loadings. The next step is solution, in this step the governing algebraic equations in matrix form and computes the unknown value of the primary field variables is assembled. Actually the FEAtures in this step such as matrix manipulation, numerical integration and equation solving are carried out automatically by commercial software. The final step is post processing, the analysis and evaluation of the result is conducted in this step.

Firstly, a three dimensional hollow shaft $3 \mathrm{~mm}$ thick, $300 \mathrm{~mm}$ long and $40 \mathrm{~mm}$ in diameter is modeled. The surface boundary conditions are applied to the shaft model as shown in Fig. 5. Fixed support is applied at one end shaft and $400 \mathrm{Nm}$ of torsion is applied on the other end of the shaft.

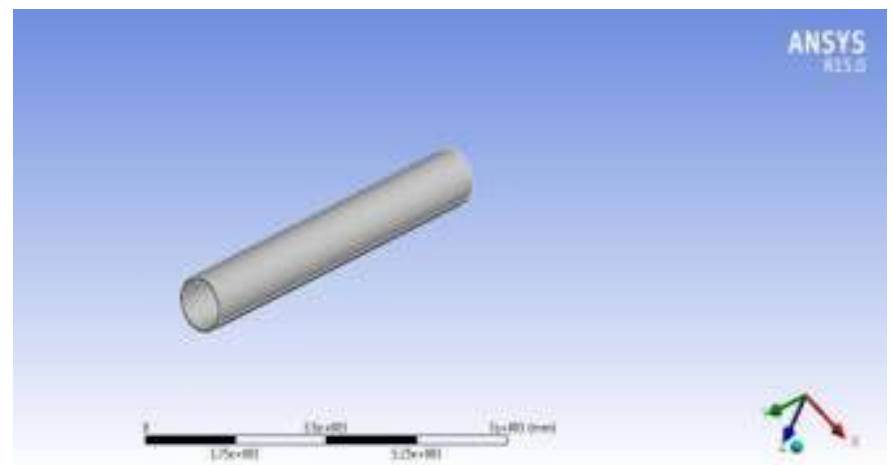

Fig. 2: Model of the Hollow Shaft

According to analytical solutions, it has been calculated that the torque applied on the Shaft is $400 \mathrm{Nm}$. As the stress is function of area which is square of the dimensional scale andloading.

Thus the building of FEA model the shaft has been modelled using shell module with thickness 3 mm. Figure below shows themeshed model for the assembly. Standard element size of $3 \mathrm{~mm}$ is used for the good results in the analysis

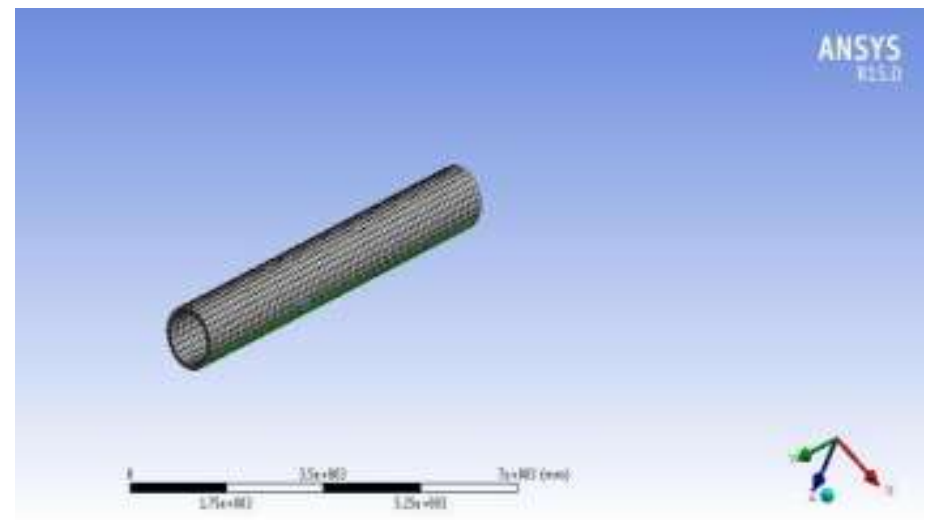

Fig. 3: Meshing of the Hollow Shaft 
The Input of fixed and free ends are given to the boundary conditions below.

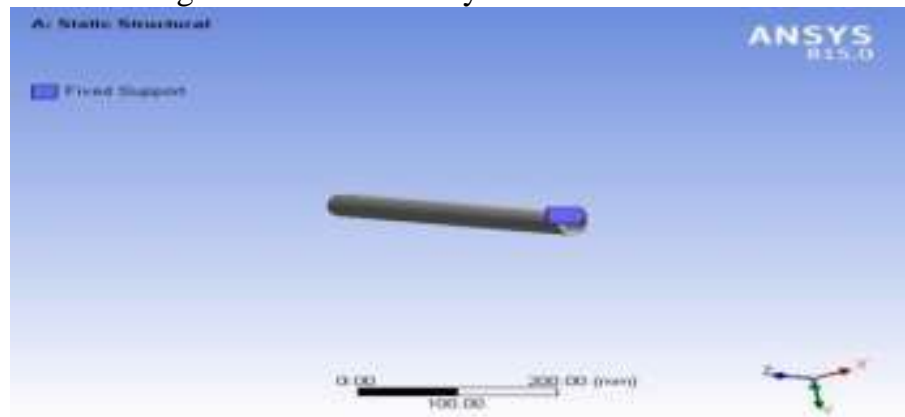

Fig. 4: fixed support of the Hollow Shaft

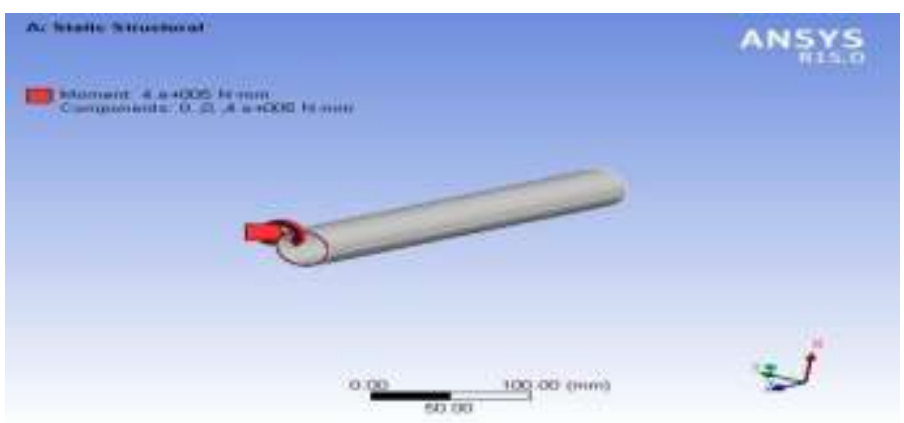

Fig. 5: Moment applied of $400 \mathrm{Nm}$ on the Hollow Shaft

Thus after applying moment of $400 \mathrm{Nm}$ with one end fixed gives the results. Figure above shows the boundary condition for the Hooke's static analysis.

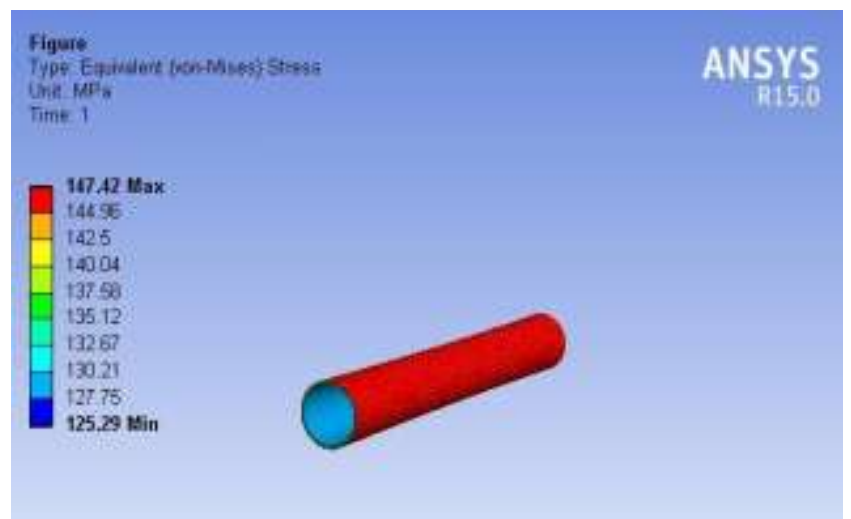

Fig. 6: Von Mises Stress plot for Hollow Shaft

Interpretation: The maximum stress is $147.42 \mathrm{MPa}$ at the throughout surface of the Hollow shaft.

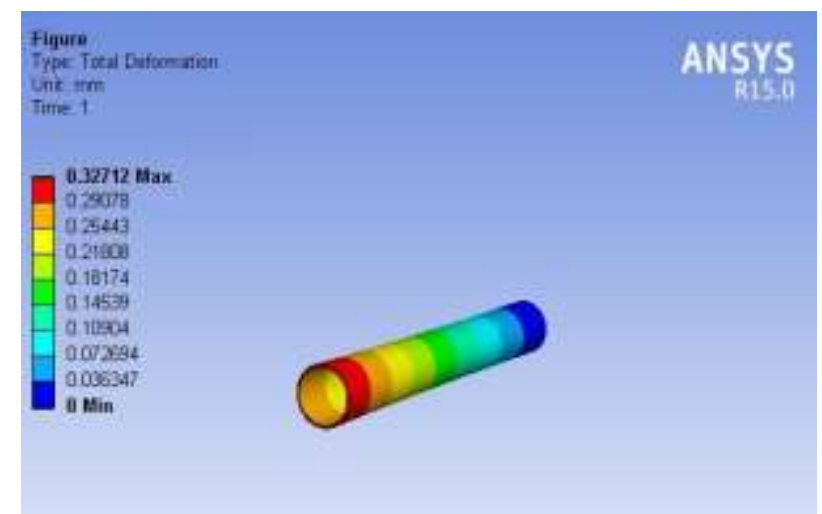

Fig. 7: Total deformation plot for Hollow Shaft 
Interpretation: The maximum deformation of the Hollow Shaft 1 is $0.327 \mathrm{~mm}$.

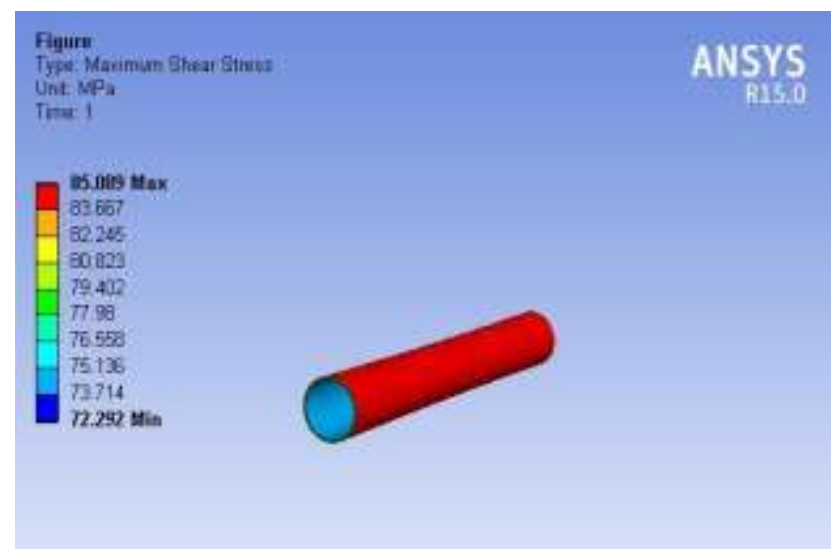

Fig. 8: Max Shear Stress plot for Hollow Shaft

Interpretation: The Max Shear Stress of the Hollow Shaft is $85.08 \mathrm{Mpa}$

\section{Modeling of the Hollow Shaft with Rib}

A hollow shaft with a rib at both ends is proposed for the output shaft of the portal axle. The proposed shaft with five parameters is modeled, as shown in Fig. Table 1 shows the material properties and the dimensions used for modeling the shaft. The proposed shaft is used as a benchmarking shaft for comparison with the optimized shaft and the hollow shaft in later section. Similarly, the proposed model of the hollowshaft with a rib, a torque of $400 \mathrm{Nm}$ is applied at one end of the shaft and the other end of the shaft is fixed. In Fig. 9, the vonMises stress determined in the ANSYS FEA softwareisMPa.

By applying boundary condition at the end of the shaft making one side fixed and applying torque at other end of $400 \mathrm{Nm}$

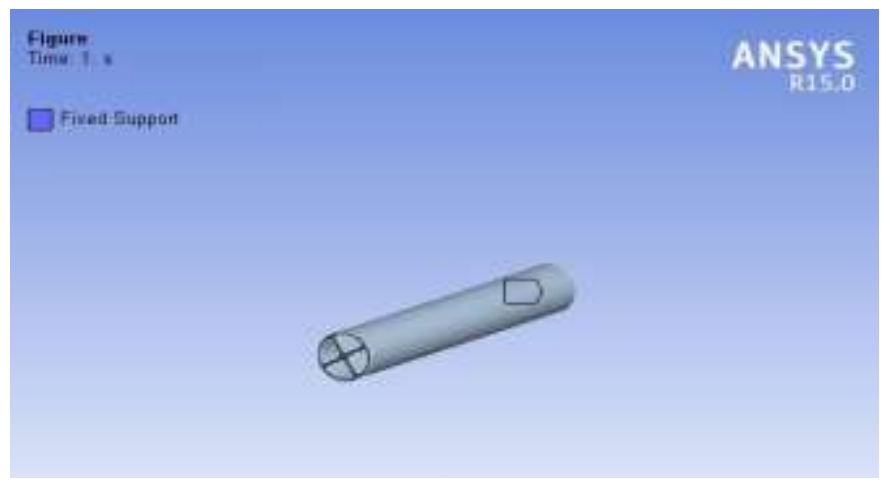

Fig. 9: Applying constraints to the Shaft with Rib

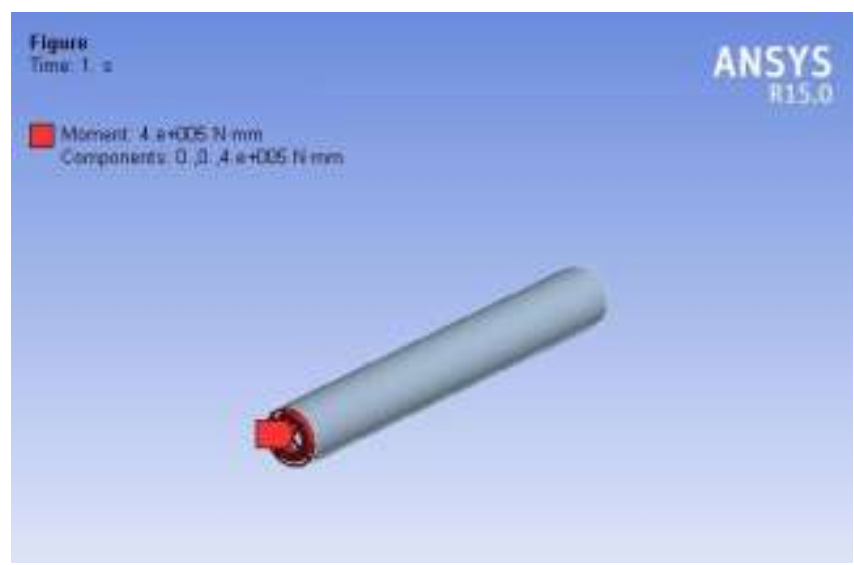

Fig. 10: Applying moment of $400 \mathrm{Nm}$ to the Shaft with Ribs 


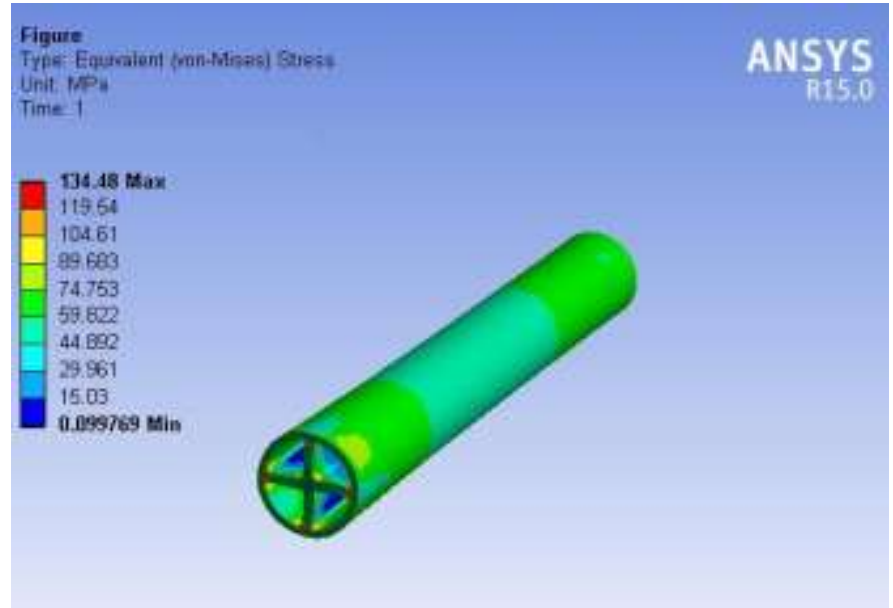

Fig. 11: Von Mises Stress plot for Hollow Shaft

Interpretation: The maximum stress is $134.48 \mathrm{MPa}$ at the throughout surface of the Hollowshaft

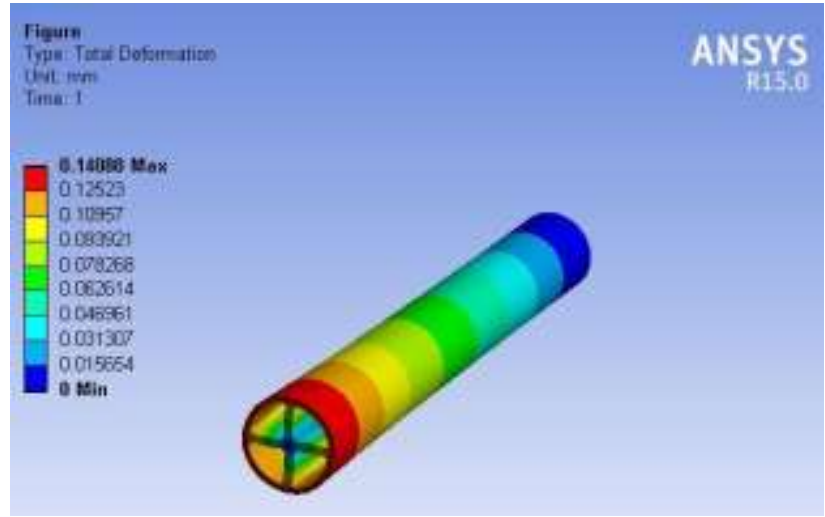

Fig. 12: Total deformation plot for Shaft with Ribs

Interpretation: The maximum deformation of the Hollow Shaft 1 is $0.14088 \mathrm{~mm}$

So now we start the changes in the various parameters of the shaft by implementing Ribs within the points of the parameters like :

a. Thickness ofShaft.

b. Thickness ofRib.

c. Depth of theRib.

d. Number ofspokes.

e. Fillet Radius of theRib.

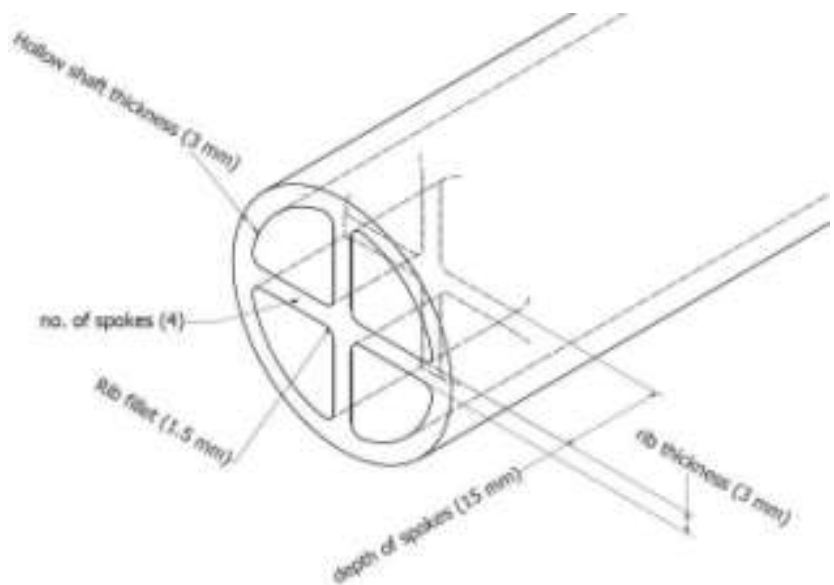

Fig. 13: The parameters to be considered for the optimization of shaft TABLE II: TAGUCHI ARRAY FOR OPTIMIZATION 
Table II: Taguchi Array For Optimization

\begin{tabular}{|l|l|l|l|l|l|}
\hline Sr. No. & $\begin{array}{l}\text { Hollow shaft } \\
\text { thickness }\end{array}$ & $\begin{array}{l}\text { Rib } \\
\text { thickness }\end{array}$ & $\begin{array}{l}\text { Depth of } \\
\text { spokes }\end{array}$ & $\begin{array}{l}\text { No. of } \\
\text { spokes }\end{array}$ & $\begin{array}{l}\text { von Mises } \\
\text { stress }\end{array}$ \\
\hline & mm & mm & mm & & MPa \\
\hline 1 & 3 & 3 & 40 & 4 & 140.76 \\
\hline 2 & 3 & 3.2 & 40 & 4 & 128.34 \\
\hline 3 & 3 & 3.2 & 45 & 4 & 119.36 \\
\hline 4 & 3 & 3.4 & 40 & 4 & 113.47 \\
\hline 5 & 3 & 3.4 & 45 & 4 & 107.83 \\
\hline 6 & 3 & 3.5 & 40 & 4 & 105.17 \\
\hline 7 & 3 & 3.5 & 45 & 4 & 102.3 \\
\hline 8 & 3 & 3.6 & 40 & 4 & 104.35 \\
\hline 9 & 3 & 3.6 & 45 & 4 & 108.77 \\
\hline 10 & 3 & 3.8 & 40 & 4 & 109.65 \\
\hline 11 & 3 & 3.8 & 45 & 4 & 110.13 \\
\hline 12 & 3 & 40 & 40 & 4 & 110.94 \\
\hline
\end{tabular}

Thus the results obtained at the dimension with shaft thickness $3 \mathrm{~mm}$, Ribs thickness $3.5 \mathrm{~mm}$, depth of the rib is $45 \mathrm{~mm}$ and the number of spokes is 4 .

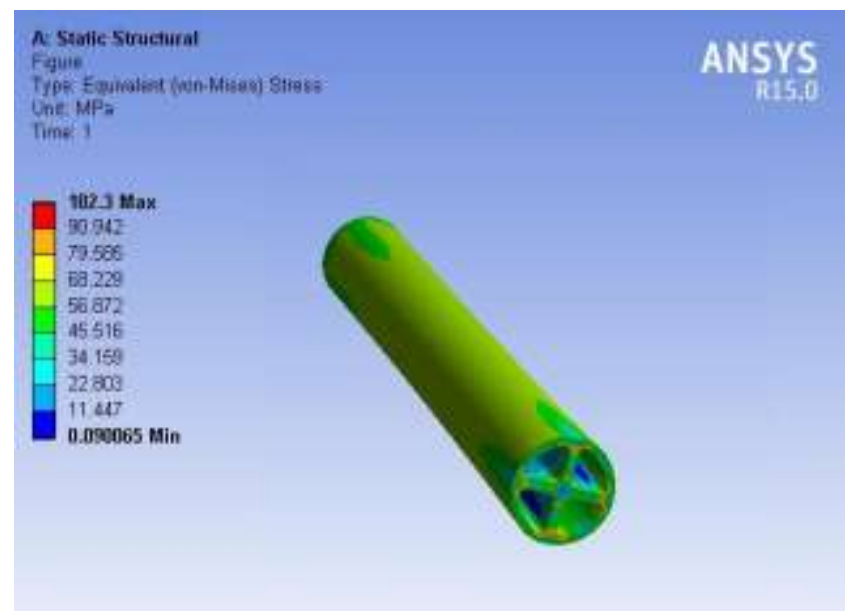

Fig. 14: Von Mises stress of the shaft with Rib

Interpretation: The maximum von mises stress is 102.3

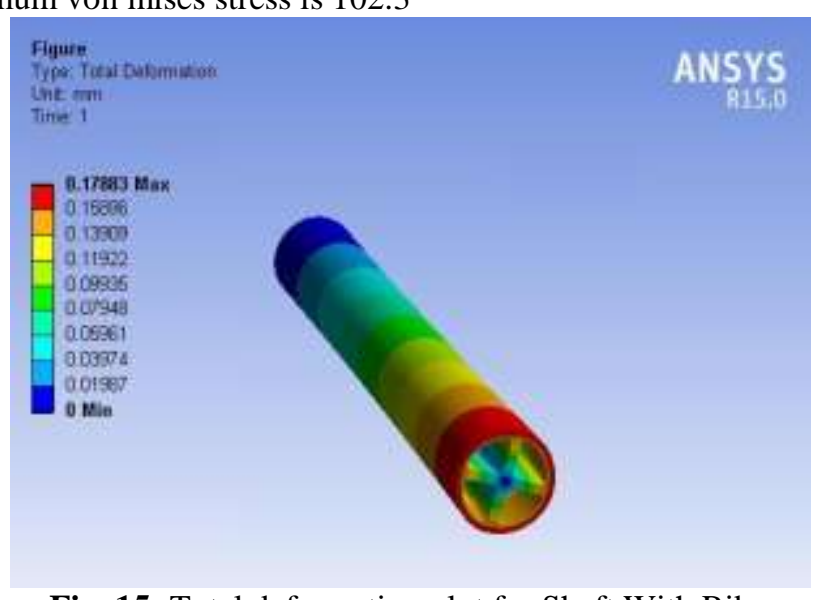

Fig. 15: Total deformation plot for Shaft With Ribs

Interpretation: TheTotal Deformation in the shaft is to be $0.1788 \mathrm{mmmaximum}$.

\section{Experimentation}

The two shaft manufactured of dimension 300mm in length and thickness of $3 \mathrm{~mm}$. The rib is inserted in the hollow shaft by welding process. The rib is having thickness of $3.5 \mathrm{~mm}$ and the depth of $45 \mathrm{~mm}$. 


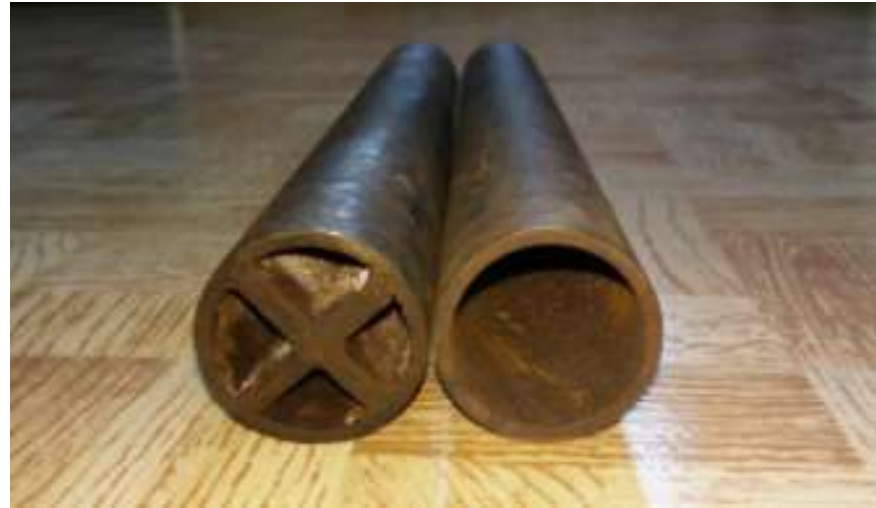

Fig. 16: shaft models Manufactured

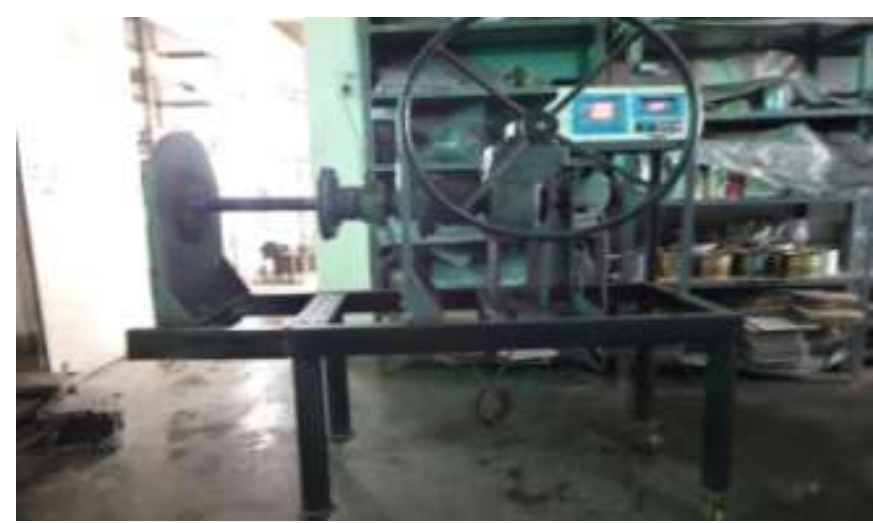

Fig. 17: Experimental setup

For experimental testing of the shaft is to be done on the Torsion Testing Machine which has a capacity of generating torque upto $1500 \mathrm{Nm}$.

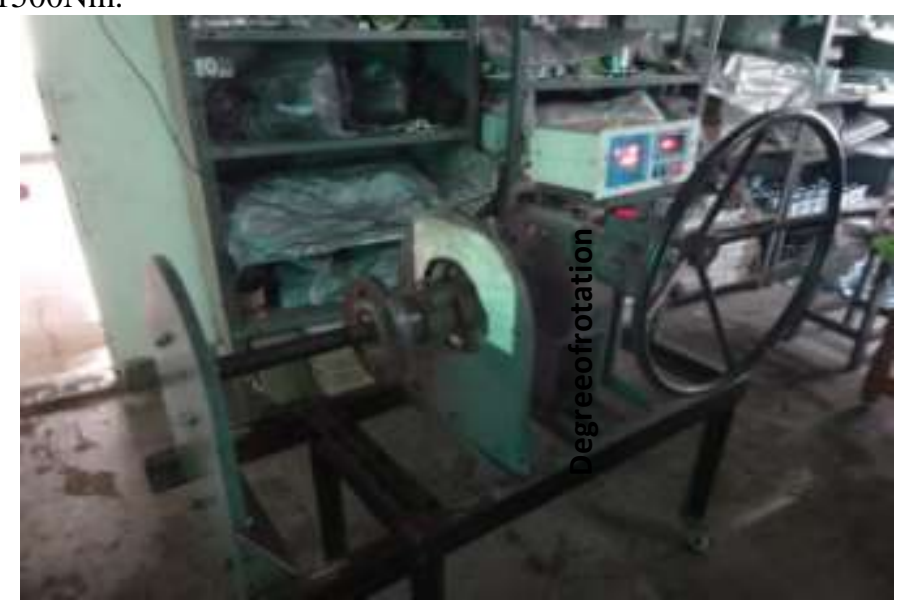

Fig. 18: The Torsion Testing Machine

\section{Results}

\begin{tabular}{|l|l|l|}
\hline Sr.No. & \multicolumn{1}{|c|}{$\begin{array}{c}\text { Torque applied } \\
(\mathbf{N m})\end{array}$} & \multicolumn{1}{c|}{$\begin{array}{c}\text { Angle of twist } \\
\text { (degrees) }\end{array}$} \\
\hline 1 & 0 & 0 \\
\hline 2 & 16 & 0.1 \\
\hline 3 & 64 & 0.2 \\
\hline 4 & 92 & 0.4 \\
\hline 5 & 108 & 0.5 \\
\hline 6 & 111 & 0.7 \\
\hline 7 & 112 & 1 \\
\hline 8 & 112 & 1.1 \\
\hline
\end{tabular}




\begin{tabular}{|l|l|l|}
\hline 9 & 113 & 1.5 \\
\hline 10 & 114 & 1.8 \\
\hline 11 & 117 & 2.0 \\
\hline 12 & 162 & 2.0 \\
\hline 13 & 288 & 2.1 \\
\hline 14 & 289 & 2.3 \\
\hline 15 & 300 & 2.4 \\
\hline 16 & 350 & 2.6 \\
\hline 17 & 400 & 2.8 \\
\hline
\end{tabular}

Table No. 2: The Test Result

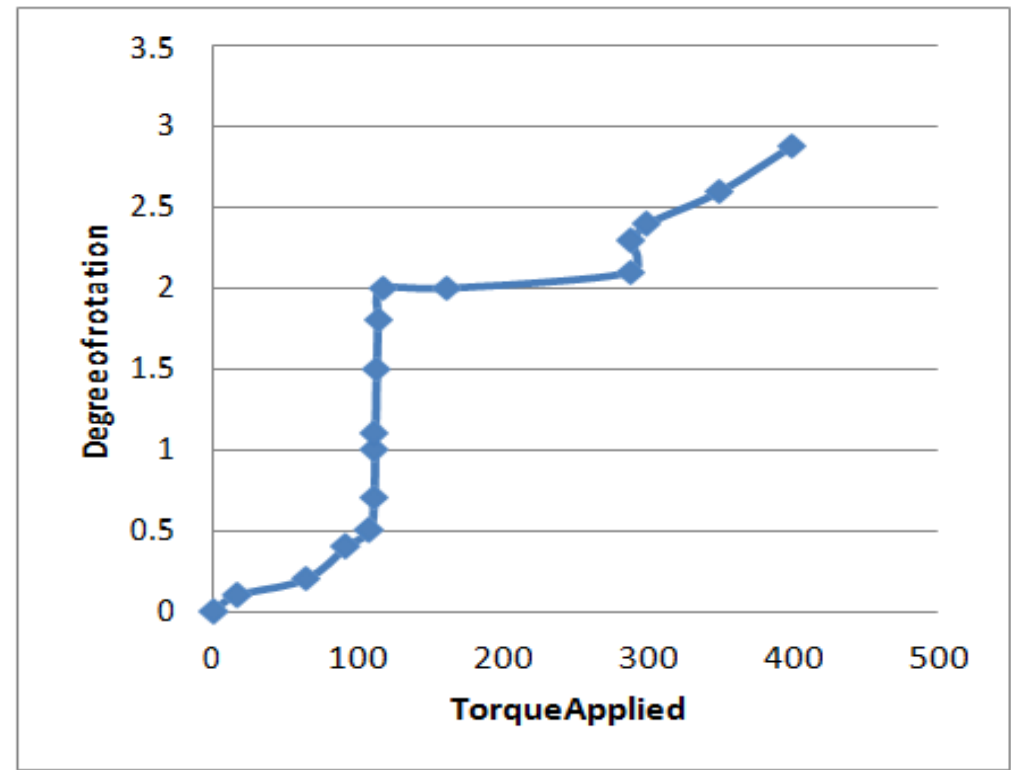

Fig. 19: The Graph Plot between Torque Applied vs Degree of Rotaion by experimentation.

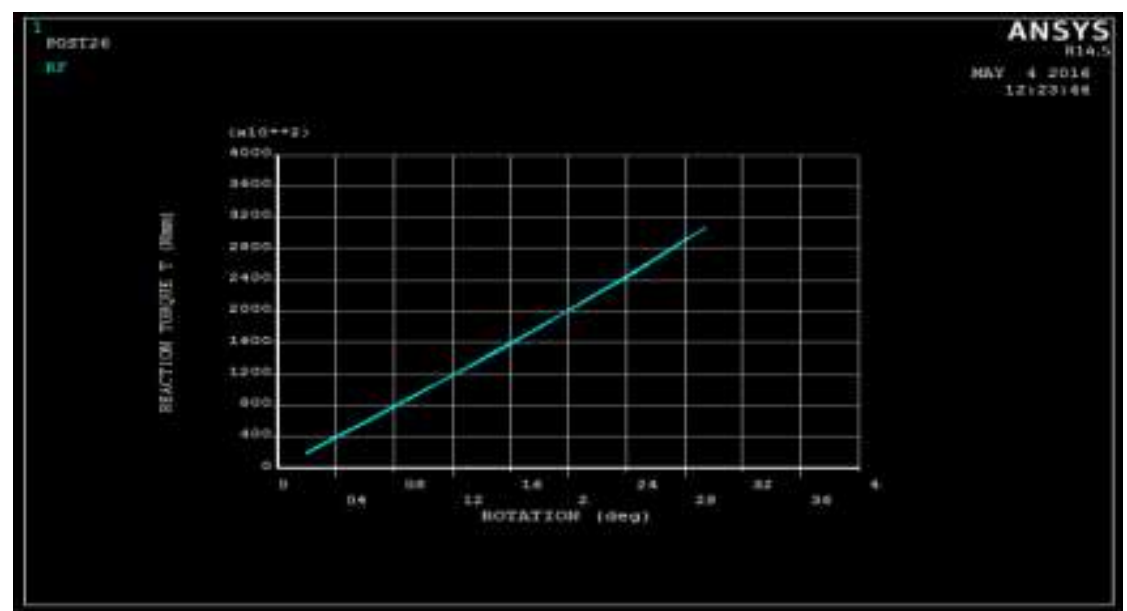

Fig. 20: The Graph Plot between Torque Applied vs Degree of Rotaion by APDL.

\section{Conclusion}

The shaft models were modeled using FEA and are validated through comparisons with the experimental results as it must sustain the torque of $400 \mathrm{Nm}$. In the analysis of the output shaft of the portal axle, the hollow shaft with a rib is proposed and the final element model is built. The optimum set of parameters of the hollow shaft with a rib is determined by using the Taguchi method: the hollow shaft thickness is $3 \mathrm{~mm}$, rib thickness is $3.5 \mathrm{~mm}$, depth of spokes is $45 \mathrm{~mm}$ and the number of spokes is4.It is found that the hollow shaft thickness affects the tensional strength of the hollow shaft with a rib the most compared to the other four parameters. Thus it must sustain the torque of $400 \mathrm{Nm}$ 


\section{Acknowledgment}

I take this opportunity to thanks Prof A. B. Gaikwad (Guide) \& Prof. A. N. Patil for valuable guidance and for providing all the necessary facilities, which were indispensable in completion of this work.

\section{References}

[1]. XuXiaolei, Yu Zhiwei, and Ding Hongxin. Failure analysis of a diesel engine gear-shaft. Eng Fail Anal;13(8):1351-7. (2006).

[2]. Ooi, J.B., Wang, X., Tan, C.S., Ho, J.H., Lim, Y.P. (2012). Modaland stress analysis of gear train design in portal axle using finite element modeling and simulation. Journal of Mechanical Science and Technology, vol. 26, no. 2, p. 575-589, DOI:10.1007/s12206011-1040-5.

[3]. Göksenli, A., Eryürek, I.B. (2009). Failure analysis of an elevator drive shaft.Engineering Failure Analysis, vol. 16, no. 4, p. 10111019, DOI:10.1016/j. engfailanal.2008.05.014.

[4]. Vijay Sekar K.S., Pradeep Kumar, M. (2012).Optimising Flow Stress Input for Machining Simulations Using Taguchi Methodology.International Journal of Simulation Modelling, vol. 11, no. 1, p. 17-28,DOI:10.2507/IJSIMM11(1)2.195.

[5]. J. B. Ooi, X. Wang, C.S. Tan, J. H. Ho, K. C. Wong and Y. P.

[6]. Lim, "Parametric optimization of the output shaft of the portal axle using finite element analysis," Journal of Mechanical Engineering Science. [Journal Impact factor: 0.473. Submitted 11 August 2012] 